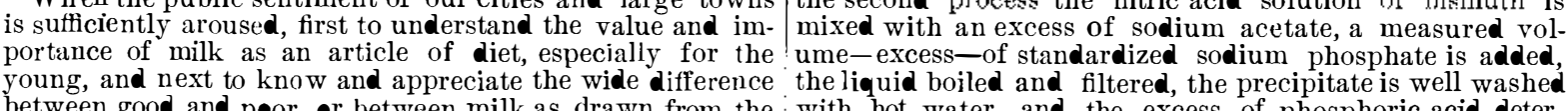
young, and next to know and appreciate the wide difference the liquid boiled and filtered, the precipitate is well washe
between good and poor, or between milk as drawn from the : with hot water, and the excess of phosphoric acid detercow and ordinary city milkman's milk, that has been sub- : mined in the filtrate the titration with a standard solutio
jected to the skimming process, even if nothing worse has of uranium acetate. The results are very accurate. Thi
hefallen it then consumers of milk will demand befallen it, then consumers of milk will demand a more in-
timate acquaintance with the producers and their method of tiinate acquaintance with the producers and their method
production: a more direct connection with the farmers then selves. Then will superior milk command a higher price
than the poorer article; then will the army of useless midale men have an opportunity to retire, and the milk business of
our large cities be conducted lyy the associated efforts of
tlose who produce the milk, alyit those alone who are entillet to the profit of this important branch of farm eco-

CHEMICAL SOCIETY, LONDON, NOVEMBER.

Dr. Ladstone, President, iv the Chair.

$a-" O n$ Some Hydrocarbons Obtained from the Homolo
of Cinnamic Acid," and b-“On Anethol and
its "Iomologues."

By W. H. Perkin, F.R.S

a.- Considerable quantities of cinnenyl-arcyiic, crotonic and angelic, and phenyl-crotonic and argelic acids were pre-
pared. The hydrocarbons were at first obtained by decomposing the acids by heat; afterwards the process proposed
by $\mathrm{F}$. Binder-viz., treating the hydrobromo acids with
bases-was found to yield more satisfact ry results. A solubases-was found to yield more satisfact iry results. A solu-
tion of hydrobromic acid i m glacial acetic acid, instead of
an aqueous solution, answered very well. The following an aqueous solution, answered very well. The following
acids were prepared and examined: Hydrobromocinneny-
lacrylic acid $\mathrm{C}_{12} \mathrm{H}_{16} \mathrm{BrO}_{2}$, fuses 85 eg. to $87 \mathrm{C}$. Hydrolacrylic acid $\mathrm{C}_{12} \mathrm{H}_{15} \mathrm{BrO}_{2}$, fuses 85 deg. to $87 \mathrm{C}$. Hydro-
bromocinnenyl-crotonic acid $\mathrm{C}_{13} \mathrm{H}_{17} \mathrm{BrO} \mathrm{O}_{2}$ crystallizes in flat, oblique prisms, fuses at $148-150$ deg. $\mathrm{C}$. On further heat
ing, $\mathrm{HBr}$ is evolved. Hydrobromocinnenyl-angelic acid $\mathrm{C}_{1}$ $\mathrm{H}_{19} \mathrm{BrO}$
a cold solution of of sodium carbonate or potassium hydrate, a cold solution oi sodium carbonate or potassium hydrate,
decompose, hydrocarbons being produced as follows: isopropylvinyl benzene boils at $203-206$ deg. C., sp. gr. at 15
deg. 8902 . Heated for a few hour to 150 deg. C., it solidifies to a transparent glassy mass. This change also takes place slowly at ordinary temperatures in daylight. The The dibromide was prepared, fusing at 71 deg. Isogropyl-
allyl-benzene boils at 229 deg. to 230 deg., sp. gr. $15 \cdot 890 ;$ dow
not solidify at 15 deg. C. Its formation may be represented

not solidify at 15 deg. C. Its formation may be represented

$\mathrm{C}_{6} \mathrm{H}_{4}\left(\mathrm{C}_{3} \mathrm{H}_{7}\right) \mathrm{CH}, \mathrm{CH}^{\prime} \mathrm{OH}_{2} \mathrm{COOH}=\mathrm{C}_{6} \mathrm{H}_{4}\left(\mathrm{C}_{3} \mathrm{H}_{7}\right) \mathrm{CH}, \mathrm{CHCH}_{3}$

Cinnenyl-crotonic acid
$\mathrm{C}_{6} \mathrm{H}_{4}\left(\mathrm{C}_{3} \mathrm{H}_{7}\right) \cdot \mathrm{CH}_{2} \mathrm{CHBr}^{\cdot} \mathrm{CH}_{2} \mathrm{COOH}=\mathrm{CH}_{6} \mathrm{H}_{4}\left(\mathrm{C}_{3} \mathrm{H}_{7}\right) \mathrm{CH}$;

$\mathrm{Hydrobromocinnenyl-crotonic} \mathrm{acid} \mathrm{CHCH}_{3}+\mathrm{HBr}+\mathrm{CO}_{2}$

Its dibromide was obtained by shaking the hydrocarbon
with bronine. It melts at 59 deg. to a colorless oil, crystallizing beautifully on cooling. Isopropylbutenyl-benzene is $\mathbf{8 8 7 5}$. It resinifies if kept in contact with the air. Its dibromide was prepared melting at 77 deg. Allyl-benzene
boils at $174-175$ deg.; sp. gr. at 15 deg. 9180 . When heated between 160-200 deg. for sixty hours, it did not undergo
any visible change. Its dibromide was obtained as a crysany visible change. Its dibromide was obtained as a crys-
talline mass, fusing at 67 deg. Butenyl-benzene, a colorless
oil boiling at 186 to 187 deg. C.; a dibromide was prepares crystallizing in needles melting at 57 deg. The two last

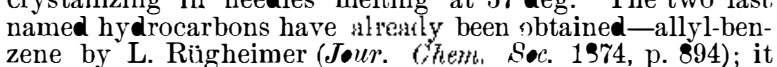
zene by $L$. Rügheimer (Jour. Chem, Soc. 1974, p. 894); it
has the same constitution as the body prepared by the author. The butenyl-benzene, however, prepared by B. $\mathrm{B}$.
Aronheim (Deut. Chem. Ges. Ber. v. 1068) is isomeric with the one now produced- "b." Ber: On gently boiling methylparoxyphenyl-acrlic acid, an oil gradually distils over
having a fennel-like odor. This body, after purification,
had the formula $\mathrm{C}_{9} \mathrm{H}_{10} \mathrm{O}$, the author proposes to call it viny had the formula $\mathrm{C}_{9} \mathrm{H}_{10} \mathrm{O}$, the author proposes to call it viny-
lic anethol; it boils about 201 to 202 deg.; melts at about thus:$\mathrm{C}_{6} \mathrm{H}_{4}\left(\mathrm{OCH}_{3}\right) . \mathrm{CH}, \mathrm{CH} \mathrm{COOH}=\mathrm{C}_{6} \mathrm{H}_{4}\left(\mathrm{OCH}_{3}\right) . \mathrm{CH}_{2} \mathrm{CH}_{2}$

An endeavor was made to prepare this substance by
Binder's reacticn. but without success. On heating methylparoxyphenyl-srotonic acid, an oil distils over, carbonic
acid being evolved; by fractional distillation, freezing, and
pressing the mass thus obtained between blotting paper,perpressing the mass thus obtained between blotting paper,pe-
fectly" pure allylic or ordinary anethol was obtained, identi cal with that obtained from oil of anise. By heating meth $\mathrm{l}$ -
paroxyphenyl-angelic acid, butenylic anethol is obtained i
an impure siate; but by treating the hydrobromo derivative paroxyphenyl-angelic acid,butenylic anethol is obtained in
an impure state; but by treating the hydrobromo derivative
of that acid with sodium carbonate, etc perfectly pure butof that acid with sodium carbonate, etc., perfectly pure but
enylic anethol is obtained; it is crystalline, fusing at 17 dee enylic anethol is obtained; it is crystalline, fusing at 17 deg
C., boiling at 242 to 245 deg.: sp. gr. at 30 deg. 9733 ; fo
mula, $\mathrm{C}_{11} \mathrm{H}_{14} \mathrm{O}$. In conclusion, the author discusses the mula, $\mathrm{C}_{11} \mathrm{H}_{14} \mathrm{O}$. In conclusion, the author discusses the formation of the hydrocarbons from the hydrobromo acids
by heating with sodium carbonate; he finds that silver ni-
trate in aqueous solution, sodium acetate and in some cases trate in aqueous solution, sodium acetate, and in some cases
even water, may be substituted for sodium carbonate, and
yet the hydrocarbon be formed, and concludes that the hyyet the hydrocarbon be formed, and concludes that the hy-
drocarbons are formed simply by the separation of hydro-
bromie acid and carbonic anhydride. The author remarks bromic acid and carbonic anhydride. The author remarks
that only the hydrocarbons and anethol containing vinyl polimerise when heated, and form compounds correspondmore from those of the compounds containing
allyl than do the latter from those of the butenyl compounds.
Dr. Gladstone said that the Society had rarely listened to
a research so productive of new and interesting substances a research so productive of new and interesting substances, be obtained by an exami
sion of these new bodies.

"On Thoo New Methods for Estimating Bismuth Volumetri-
cally," by M. M. Muir. - Chancel has shown (Jahrber. 1860, cally, that bismuth is precipitated in the form of phos phate by the addition of a soluble phosphate to solution of
the metal in nitric acid. Both processes are based on this fact. In the first bismuth is thrown down from nitric acid
selution after partial neutralization with ammonia, by adsolution after partial neutralization with ammonia, by ad-
dition of a standard solution of sodium phosphate; the Tellow Glass Better than Blue.-According to M supernatant liquid on a slab with warm ammonium moly- $\mid$ Fano, neurosis of the cye has been successfully treated by
bate solution. The results are approximately accurate. In

These two liquid ditolyls gave identical results on oxida-
ion; (1) ortho-para-tolyl-phenyl-carbonic acid $\mathrm{H}_{18}\left\{\mathrm{CH}_{3}\right.$ a white powder melting at 176 deg. C. white powder which sublimes before fuming, and finally
erephthallic acid. The above experiments show that when erephthallic acid. The above experiments show that when
odium acts on a mixture of para and ortho-brom toluene
wo isomeric ditolyls are produced, and dipara and the wo isomeric ditolyls are produced, and dipara and the
ortho-para compounds. The author gives graphic formula
showing the constitutional rolations of the above bodies, showing the constitutional rolations of the above bodies,
and concludes by stating that he hopes to be able to prepare cid, and, thus confirm the constitution of phenanthrene
a When a solution of a manganous salt in strong nitric
cid is warmed with the addition of crystals of potassic
hlorate, the whole of the manganese is precipitated as chlorate, the whole of the manganese is precipitated as
manganous manganate. If a salt of iron be present, adouble manganate of iron and manganese, $2 \mathrm{Fe}_{2}\left(\mathrm{MnO}_{4}\right)_{3}$. Mn $\mathrm{M}$.
$\mathrm{In} \mathrm{O}_{3} 12 \mathrm{H}_{2} \mathrm{O}$, is precipitate no other metals seem to $\mathrm{be}$ precipitated with manganese under the same conditions. act unattacked by caustic alkalies. Hywlroshloric acid hurous acid first attacks the iron, setting free manganing a considerable degree of coherence. The manganese
ing $\mathrm{F}_{2,2}\left(\mathrm{M}_{12} \mathrm{O}_{4}\right)_{3}+6 . \mathrm{SO}_{2}=\mathrm{Fe}_{2}\left(\mathrm{SO}_{1}\right)_{3}+3 . \mathrm{MH}_{11} \mathrm{SO}_{1}$

The principal interest in the above reaction is that it furnishes a good method of separating iron from aluminum,
etc., without the use of pure caustic soda. The iron com-
pound appears under the microscope as thin flexible plates of

METABROMOBENZENESULPHONIC ACID. By Alfred Thomas.

Pure benzencsulphonic acid was prepared and neutralized
with silver carbonate, and the still warm liquid treated with bromine until no further precipitate of silver bromide was
produced; the liquid was then evaporated on the water-bath cutralized with barium carbonate, and further evaporated
crystals of barium metabromobenzenesulphonate separated, tained some barium benzene-sulphonate. From the barium salt the free acid was prepared by treatment with dilute sulwas obtained by the action of nitric acid; the potassium and
mmonium salts are anhydrous, the barium salt is $2 \mathrm{C}_{6} \mathrm{H}_{3} \mathrm{Br}$ mmonium salts are anhydrous, the barium salt is $\left\{\mathrm{C}_{6} \mathrm{H}_{3} \mathrm{Br}\right.$
$\left.\left.\mathrm{NO}_{2}\right)\left(\mathrm{SO}_{2}\right)\right\}_{2} \mathrm{Ba} .3 \mathrm{H}_{2} \mathrm{O}:$ the calcium salt contains $6 \mathrm{H}_{2} \mathrm{O}$, the ead salt crystalizes with $3 \mathrm{H}_{2} \mathrm{O}$, and the silver salt has $1{ }_{2}^{1} \mathrm{H}_{2}$
O. The chloride of this acid melts at $83^{\circ}$, after crystallization from ether. By the action of ammonium sulphide
this acid forms amidometabromobenzene sulphonic acid. of this acid forms amidometabromobenzene sulphonic acid, of
which the potassium salt is anhydrous, whilst the barium
salt crystallizes with $1 \frac{1}{2} \mathrm{H}_{2} \mathrm{O}$, and the lead salt with $2 \mathrm{H}_{2} \bullet$. By treating this acid with hydriodic acid and amorphous
phosphorus at $110^{\circ}$, the bromine is removed, and an amidotance it was recognized as the orth acid, whence the nitrocid is orthonitrometabromobenzene-sulphonic acid; moreove
he relative positions of the lateral chains in orthoamid etabromobenzene-sulphonic acid was found to be:-

$$
\text { and not }
$$

derivatives and treatment with hydrobromic acid, paradibro-
mobenzene-sulphonic acid resulted (where the two Br groups are para with respect to one another, one being meta and one ortho with reference to the sulphonyl-group). The potass-
ium salt of this dibrominated acid crystallizes with $1 \mathrm{H}_{2} \mathrm{O}$, When orthonitrometabromobenzene-sulphonic acid is
heated to $160^{\circ}$ with alcoholic ammonia, the bromine is metamidobenzene-sulphonic acid the barium salt of which metamidobenzene-sulphonic acid the barium salt of which
crystallizes with $1 \frac{1}{2} \mathrm{H}_{2} \mathrm{O}$; a little of a body melting at $151-$ $152^{\circ}$ was firmed, probably an impure paranitrobrom obenzene,
as it seemed to form parabromaniline on reduction with tin as it seemed to form parabromaniline on The foregoing is an example of the progress of the nd ish terms used by modern chemistry.-[Ed. S. A.]
The President, Prof. G. C. Foster, lately described and acts on the same principle as Sir W. Thomson's trap-doo form of apparatus, but can be constructed at a very moderate
cost. To one arm of a balance is suspended, by silk fibres, zinc, which hangs horizontally in the plane of a sheet o about 1 inch below is a tlat sheet of zinc, also horizontal. An electrical connection is formed between the guard-plate and of using the apparatus to determine the potential reauired for a spark to pass from a Holtz machine through varying thicknesses of air was explained. When the balance ha 1 grm., is introduced into the scale-pan, and the guard-plate spark-measurer, are connected with the conductors of the machine. If this be now set in action, and the knobs of the spark-measurer be gradually separated, a point will be
reached at which the attraction upon the suspended disk just overcomes the excess weight in the balance-pan. The length difference of the potential causing the spark is given by the
formula(2) orthopara-diphenyl-carbonid acid $\mathrm{C}_{12} \mathrm{H}_{18} \begin{cases}\mathrm{CO} & \mathrm{OH} \\ \mathrm{CO} & \mathrm{OH}\end{cases}$ "On a Nero Manganese Reaction," by J. B. Hannay.

from the circumstance that on conversion into the diazo$i$ whilst the barium salt forms needles containing $1_{2} \mathrm{H}_{2} \mathrm{O}$, and
prisms with $5 \mathrm{H}_{2} 0$.

\section{$e$
$-\sqrt{ } 8 \mathrm{~F}$,}

where $a$ is the radius of the attracted disk, $e$ its distance from the attracting-plate, and $\mathrm{F}$ the force of attraction in dynes.
In the apparatus exhibited $a$ had the value $5.195 \mathrm{c} . \mathrm{m}$., and the value $2 \cdot 4 \mathrm{c.m}$. , whence, if $w$ be the excess weight in
grammes-so that $\mathrm{F}=981 w$-the difference of potential becomes $39 \sqrt{ }$. The proper action of the apparatus depends
essentially upon the attracted disk being accurately in the essentially upon the attracted disk being accurately in the
same place with the guard-plate. To tacilitate this adjust-
ment each of the silk fibres by which the disk is suspended is attracted to a screw, by which it can be separately raised or lowered; and by means of another screw the small brass
plate holding the suspending screws can be raised or lowered the action of the apparatus: these were taken from a set of experiments in which the difference of potential needed to ults of a few of the shortest and longest sparks measured

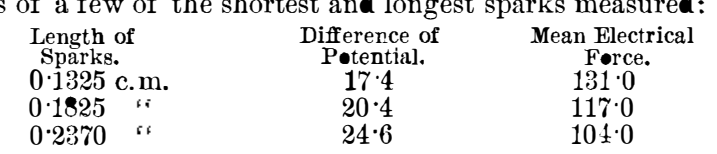

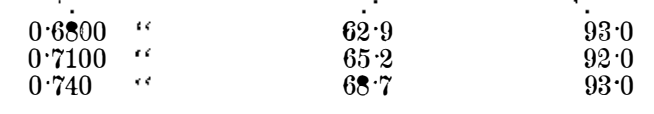

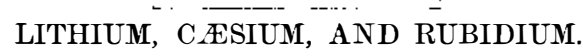

Lepidolite contains very considerable quantities of alumi-

Alumi

Ferric oxide.

Alkaline eart

28.54
50.39

The mineral is melted in a reverbatory, suddenly chilled nd pulverized. It is then treated with an equal weight of
monohydrated sulphuric acid in a vat lined with lead, and heated with a current of steam. The paste produced is then drawn off before it solidifies, and allowed to stand for
twenty-four hours. An excess of water is then added, and
the whole is then boiled, and filtered at a boil in a leaden growing cold. The liquid is concentrated to $40^{\circ}$ B. in lead-
filteresters growing cold. The liquid is concentrated to $40^{\circ} \mathrm{B}$. in lead-
en boilers heated by steam, and is then allowed to crystallize.
On cooling all the rubidium and the cæsium are coposited as an alum along with a very little potassium. The alums of cæsium and rubidium are separated by a series of crys-
tallizations. The mother-liquors containing the potash alum and an excess of sulphate of alumina and free sulphuric acid are mixed with a cold concentrated solution of carbonate of
potash (25 parts of dry carkonate to 100 of chilled lepidolite). potash (25 parts of dry carkonate to 100 of chilled lepidolite).
The alum is deposited on cooling as a crystalline powder containing mere traces of iron. The mother-liquors of
the alum, still acid, are diluted with water, treated with an excess of carbonate of potash to throw down the alumina,
filtered and evaporate to $35^{\circ} \mathrm{B}$. Sulphate of potash and portion of sulphate of soda crystallise out on cooling. The mother-liquors are again digested with powdered carbonate
of soda to precipitate lithia. The small quantities of phosphate of soda. The lithic phosphate thus obtained is melted with lime, and the lithia thus liberated is extracted
in boiling water. The crude carbonate of lithia precipitated in boiling water. The crude carbonate of lithia precipitated
is re-dissolved in boiling water, and causticised with lime. is re-dissolved in boiling water, and causticised with lime.
The clear solution, concentrated to $40^{\circ} \mathrm{B}$., is then treated with pure carbonate of scda. Carbonate of lithia is then water, then with alcohol, and finally dried-Dingl. Pol. EXPERIMENTS ON PRODUCTION OF PLANTS. Prof. H. HoFfarans has been for twenty-two years en-
aged in experiments on the modification of plants by intergaged in experiments on the modification of plants by inter-
ference in their external vital conditions. He concludes that
the cause of the evolution of new species lies, not, as Darwin the cause of the evolution of new species lies, not, as Darwin
believes, $m$ outward influences, but in internal organic laws, whose nature is at present concealed.

THE HONEY TRADE. By Andrew J. Lawson.

THE honey trade is a very quiet one, yet there is a good pied comparatively little attention on the part of the statistipied comparatively little attention on the part of the statisti-
cians of the country, who have made a study of the produc
tion of the United States a specialty. But itis ascertained make the production of honey a part of their occupation
and it is also estimated that these persons have twenty-five apiaries each, a full swarm being estimated at about 20,000 bees. This will give a total of $75,000,000$ bees employed i as a whole. A few numerical results were given to illustrate that over 150,000 persons in this country are engaged in the keeping of bees. This includes farmers and others, who 